\title{
Proses Pengolahan CPO (Crude Palm Oil) menjadi RBDPO(Refined Bleached and Deodorized Palm Oil) di PT XYZ Dumai
}

\author{
Soni Fajar Mahmud \\ Program Studi Teknik Industri, Sekolah Tinggi Teknologi Dumai \\ Jl. Utama Karya Bukit Batrem II \\ e-mail:sfajarmahmud@gmail.com
}

\begin{abstract}
ABSTRAK
Crude Palm Oil (CPO) merupakan minyak mentah yang di dalamnya masih mengandung getah, dan bahan-bahan pencemar berupa kotoran maupun flavor yang tidak diinginkan. Untuk itu, sebelum diolah menjadi berbagai produk olahan minyak dan lemak, perlu dilakukan proses pemurnian CPO menjadi Refined, Bleached and Deodorized Palm Oil (RBDPO). RBDPO adalah turunan pertama dari pengolahan CPO yang merupakan produk setengah jadi yang membutuhkan proses yang cukup panjang melalui tahapan-tahapan. Proses produksi minyak CPO yang dilakukan pada plant refinery PT XYZ adalah proses pemurnian (refine) dan pemisahan (fractionation). Proses pemurnian, adalah proses mengubah CPO menjadi RBDPO, meliputi tahap degumming dengan asam fosfat, bleaching dengan activated bleaching earth, dan deodorisasi dengan menggunakan stripping agent berupa steam. Tujuan dari proses pemurnian adalah untuk meningkatkan kualitas dan mutu minyak dengan cara menghilangkan komponen-komponen minor yang dapat mempengaruhi kualitas dan stabilitas minyak
\end{abstract}

Kata Kunci: Minyak, Crude Palm Oil, Refined, Bleached and Deodorized Palm Oil

\begin{abstract}
Crude Palm Oil (CPO) is crude oil which still contains sap, and pollutants in the form of dirt or unwanted flavor. For that, before being processed into various oil and fat processed products, it is necessary to refine the CPO to become RBDPO. RBDPO is the first derivative of CPO processing which is a semi-finished product which requires a long process through the stages. The CPO oil production process carried out at PT ASK's refinery plant is a refine process and a fractionation. Purification process, is the process of converting CPO to RBDPO, including the degumming stage with phosphoric acid, bleaching with activated bleaching earth, and deodorization using a stripping agent in the form of steam. The purpose of the purification process is to improve the quality and quality of oil by eliminating minor components that can affect the quality and stability of oil.
\end{abstract}

Keywords: Oil, Crude Palm Oil, Refined, Bleached and Deodorized Palm Oil

UNITEK. Vol. 12 No. 1 Januari - Juni 2019

| p-ISSN 2089-3957 | e-ISSN 2580-2585 


\section{Pendahuluan}

Minyak sawit didapatkan dari mesocarp buah pohon kelapa sawit, secara alami berwarna merah karena kandungan beta-karoten yang tinggi. Minyak sawit berbeda dengan minyak inti kelapa sawit (palm kernel oil) yang dihasilkan dari inti buah kelapa sawit. Menurut Naibaho (2012), minyak kelapa sawit CPO berbeda dengan minyak inti kelapa sawit. Perbedaan pada warna (minyak inti sawit tidak memiliki karotenoid sehingga tidak berwarna merah), dan asam lemak penyusunnya. Minyak sawit mengandung $41 \%$ lemak jenuh, minyak inti sawit $81 \%$.

Industri pengolahan Crude Palm Oil (CPO) dan turunannya merupakan salah satu contoh sektor industri yang memberikan kontribusi yang besar bagi pendapatan negara. Dalam mengembangkan dan meningkatkan industri ini diperlukan ilmu pengetahuan serta penguasaan teknologi sehingga bangsa Indonesia mampu bersaing dengan negara lainnya. (Latifah, 2016). Salah satu jenis produk samping (by product) Palm Fatty Acid Distillate (PFAD) yang merupakan produk samping dari proses Refined Bleached and Deodorized Palm Oil (RBDPO) minyak sawit.

Minyak kelapa sawit merupakan bahan baku pembuat biodiesel yang sangat mudah diperoleh. Produk-produk turunan minyak sawit yang dapat digunakan sebagai bahan baku biodiesel diantaranya: CPO (Crude Palm Oil), CPO Low Grade (kandungan FFA yang tinggi), PFAD (Palm Fatty Acid Destilate), dan RBDPO (Refined Bleached Deodorized Palm Oil). Dari semua turunan minyak sawit, RBDPO adalah turunan minyak sawit yang mengandung kadar asam lemak bebas paling rendah. Hal ini disebabkan karena RBDPO merupakan hasil dari proses penyulingan untuk penjernihan dan penghilangan bau dari minyak kelapa sawit kasar (CPO) yang kemudian diuraikan lagi menjadi minyak sawit padat (RBD Stearin) dan minyak sawit cair (RBD Olein). Proses penguraian antara minyak sawit padat dan minyak sawit cair dapat dilakukan dengan beberapa cara, antara lain: mechanical pressing solvent chrystalization amd hydrophylization (Riegel,s, 1963).

Metode mechanical pressing merupakan cara paling sederhana yang mendidihkan asam lemak pada sebuah bejana dan kemudian didinginkan. Setelah itu bahan tersebut akan membentuk dua fasa yaitu kristal (padat) dan cairan (cair). Fasa padat adalah stearin dan fasa cair adalah olein. Secara keseluruhan hasil dari proses penyulingan CPO ini akan menghasilkan $73 \%$ olein (fasa cair), $21 \%$ stearin (fasa padat), 5\% destilat asam lemak minyak sawit (Palm Fatty Acid Destilate / PFAD) dan 0,5\% buangan. Hasil ini sangat jauh berbeda dibandingkan pengolahan biodiesel menggunakan CPO, yang mana ketika CPO didiamkan juga akan terbentuk fasa padat sebesar $80 \%$ dan fasa cair sebesar $20 \%$.

PT XYZ Dumai adalah anak perusahaan bagian refinery pada PT Meridan Surya Sejati Plantation Bangsal Aceh Dumai di kota Dumai ada yang bergerakdibidangpengolahanCrude Palm Oil (CPO) menjadi Refined, Bleached and Deodorized Palm Oil (RBDPO). CPO merupakan minyak mentah yang di dalamnya masih mengandung getah, dan bahan-bahan pencemar berupa kotoran maupun flavor yang tidak diinginkan. Untuk itu, sebelum diolah menjadi berbagai produk olahan minyak dan lemak, perlu dilakukan proses pemurnian CPO menjadi RBDPO. RBDPO adalah turunan pertama dari pengolahan CPO yang merupakan produk setengah jadi yang membutuhkan proses yang cukup panjang melalui tahapantahapan.

\section{Metode Penelitian}

Metode penelitian yang dilaksanakan dengan melakukan perbandingan antara teori yang sudah diperoleh dengan kondisi di lapangan, yaitu dengan melakukan observasi dan wawancara. Dari observasi yang dilakukan, saya mengamati mesin dan peralatan yang digunakan, alur proses yang berjalan, serta macam-macam standar yang sudah ditetapkan dan menjadi acuan dalam proses produksi oleh pihak perusahaan. Selain itu, dengan melakukan wawancara terhadap pembimbing lapangan dan operator yang bertugas, saya memperoleh banyak informasi dan pengetahuan yang baru berkaitan dengan alur produksi. 


\section{Hasil dan Pembahasan}

\section{Proses Physical Refining (Pemurnian Fisik)}

Proses physical refining merupakan proses pemurnian fisik pada CPO yang bertujuan untuk menghilangkan FFA, warna, dan bau pada minyak. Untuk menghilangkan FFA, warna, dan bau, dibutuhkan proses deodorisasi, pada suhu tinggi dan tekanan vakum, dengan cara menguapkan FFA yang memiliki volatilitas lebih tinggi dari komponen minyak. Namun pada kondisi suhu tinggi dan tekanan vakum, kemungkinan terjadi efek samping proses seperti reaksi-reaksi isomerisasi, polimerisasi dsb, yang dapat menurunkan kualitas minyak. Oleh sebab itu, untuk mencegah dan meminimalisir efek samping tersebut, sebelum proses deodorisasi, dilakukan proses pre-treatment (degumming) dan bleaching pada minyak, yang bertujuan untuk menghilangkan impuritis-impuritis pada minyak.

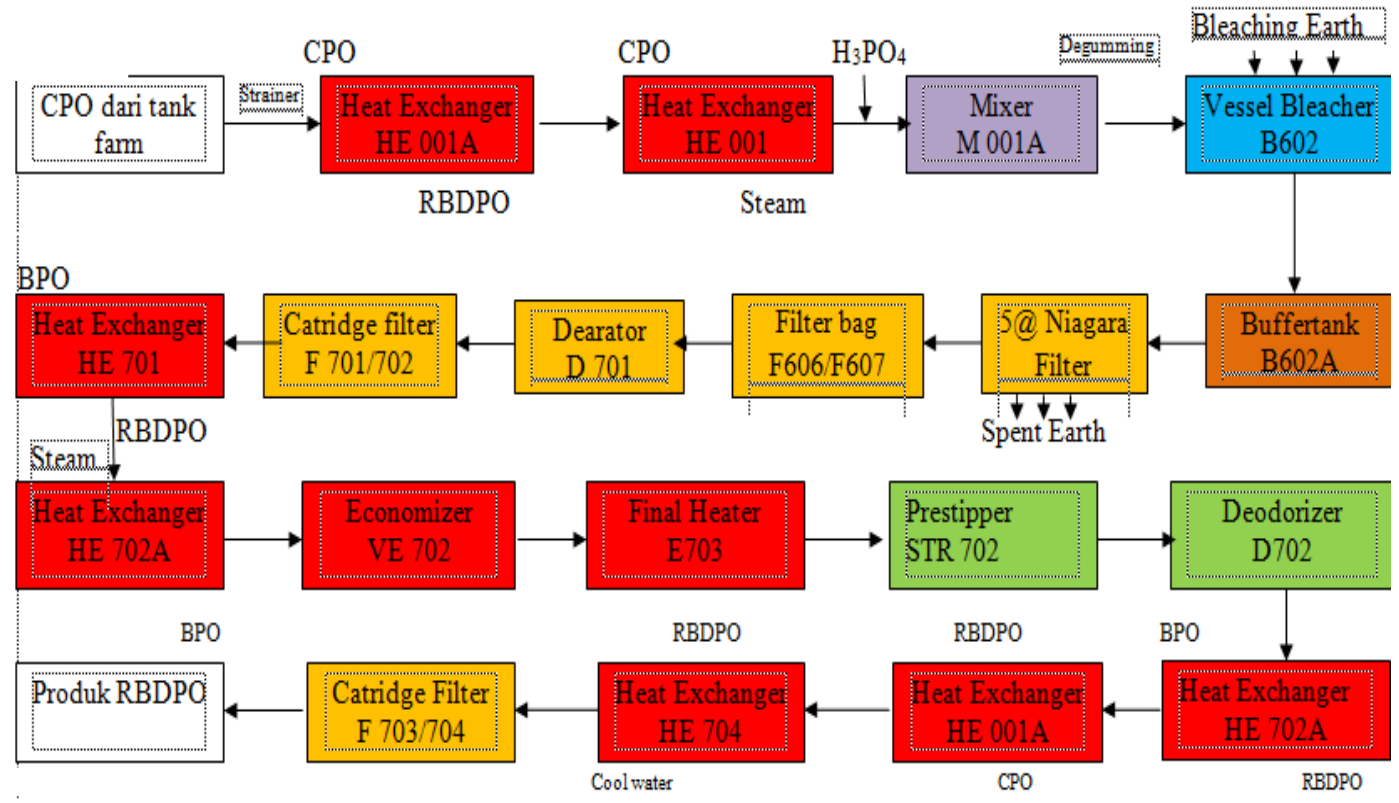

Gambar 1. Diagram Alir Proses Pengolahan CPO menjadi RBDPO di PT XYZ

Sedangkan untuk proses secara garis besar dari proses pengolahan CPO menjadi RBDPO dapat dilihat pada Gambar 2. 


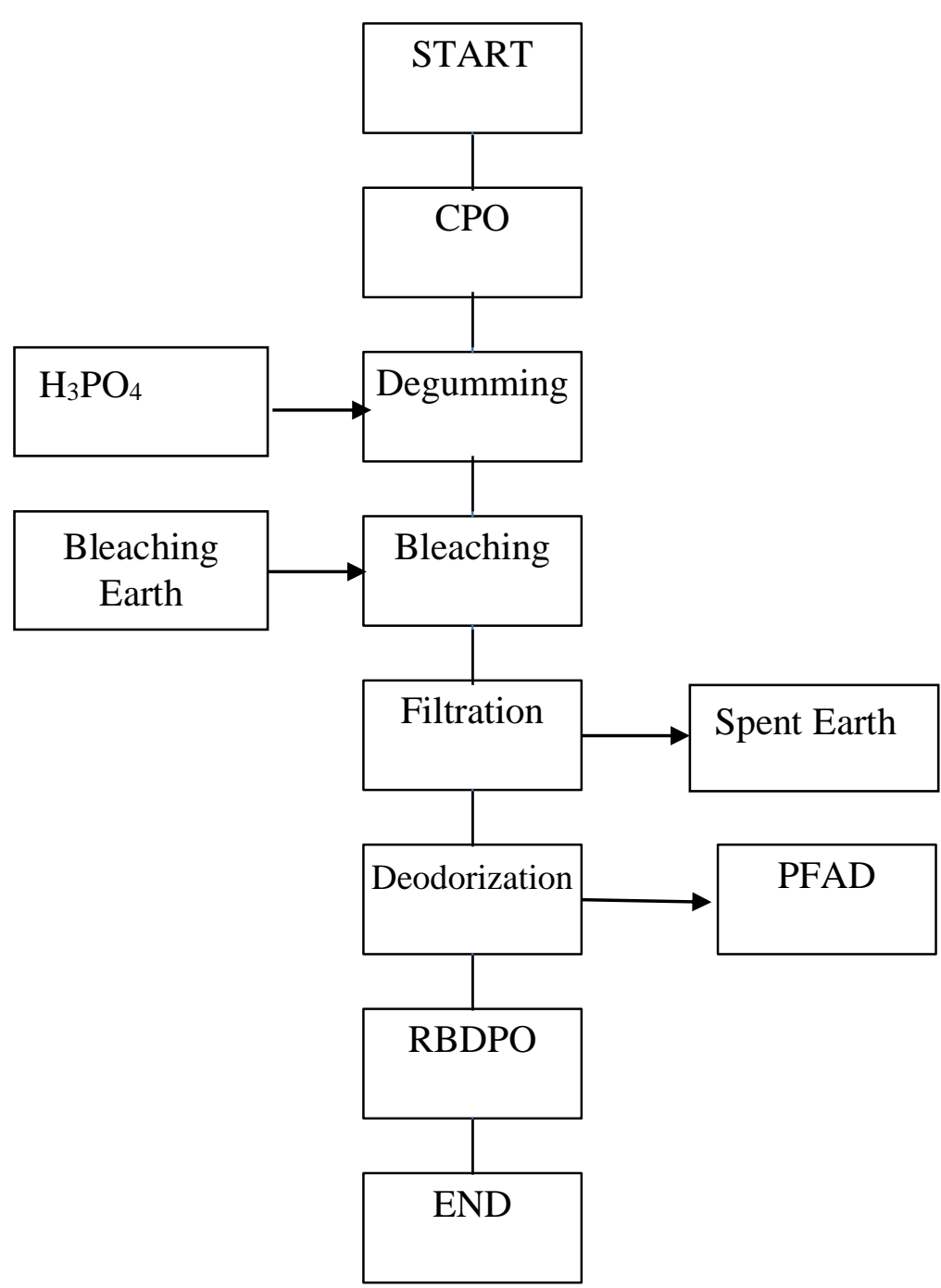

Gambar 2. Diagram Aliran Umum Proses Pengolahan CPO menjadi RBDPO

\section{Heating Process}

Sebelum masuk pada tahap degumming, pada awalnya minyak CPO dilakukan perlakuan panas, dengan mengalirkan CPO dari tangki penampungan (tank farm) menuju alat penukar panas (heat exchanger) yang berbentuk gasketed plate untuk dipanaskan.Gasketed plate heat exchanger (PHE)merupakan sebuah alat dengan konsep menukarkan panas (kalor) di antara dua fluida (media), dimana fluida dingin menerima panas dan fluida panas melepaskan panas. Terdapat beberapa plat tipis berbahan stainless steel yang tersusun dalam gasketed plate heat exchanger sehingga memungkinkan terjadinya banyak kontak antara fluida panas dengan fluida dingin. Tujuan perlakuan panas ini adalah untuk mempercepat penguapan moisture dan mendapatkan suhu CPO yang sesuai dengan suhu untuk proses degumming dan bleaching agar reaksi pencampuran antara CPO dan $\mathrm{H}_{3} \mathrm{PO}_{4}$ di degumming section berlangsung sempurna.

Pada saat yang bersamaan, minyak $\mathrm{CPO}$ bersuhu $40^{\circ} \mathrm{C}-50^{\circ} \mathrm{C}$ dan minyak RBDPO (Refined Bleached Palm Oil) bersuhu $140^{\circ} \mathrm{C}-150^{\circ} \mathrm{C}$ masuk melalui inlet PHE dan keluar melalui outlet PHE dengan arah yang berlawanan. Kedua media ini melakukan pertukaran kalor yang terjadi pada plat-plat PHE sehingga suhu CPO yang keluar adalah $75^{\circ} \mathrm{C}-80{ }^{\circ} \mathrm{C}$ sedangkan suhu RBDPO yang keluar adalah 
$130^{\circ}$ C.Selanjutnya CPO dipanaskan lagi dengan PHE sehingga suhu CPO mencapai $100^{\circ} \mathrm{C}-110^{\circ} \mathrm{C}$. Setelah itu, CPO dapat masuk ke proses degumming.

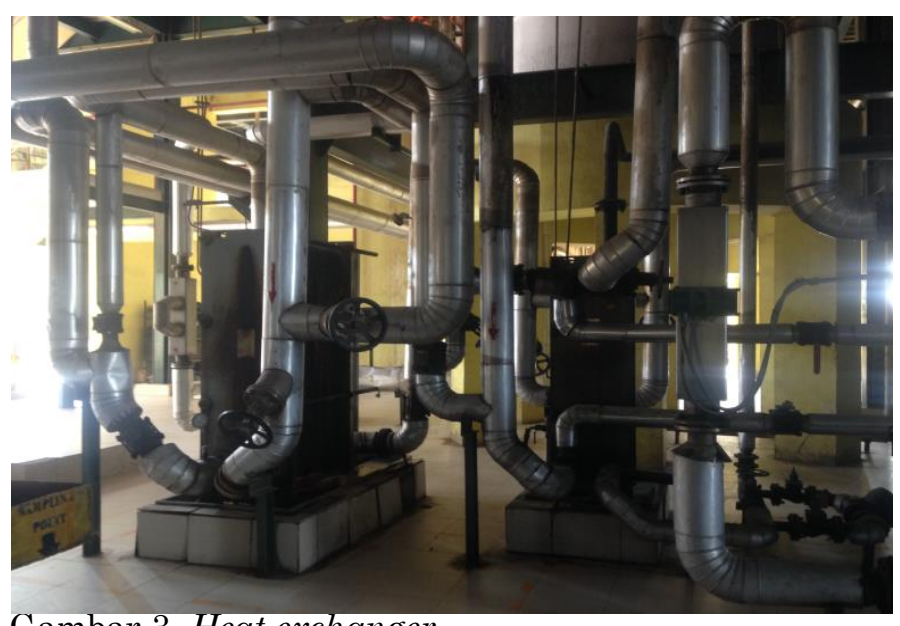

Gambar 3. Heat exchanger

Gambar 3 adalah heat exchanger dimana fungsi umumnya ialah untuk memindahkan energi panas antara dua atau lebih fluida dan terjadi pada temperatur yang berbeda antara fluida, dimana fluida tersebut ada yang bertindak sebagai fluida panas (hot fluid) dan yang lain bertindak sebagai fluida dingin (cold fluid).

\section{Degumming Process}

Proses degumming adalah proses pengikatan gum dan impurities terdiri dari komponen utama, yaitu fosfolipid, fosfotida, resin, serat-serat pengotor pada CPO. Secara umum, proses degumming dapat dibedakan menjadi water degumming, dry degumming, enzymatic degumming, membrane degumming, dan acid degumming. Namun pada plant refinery PT XYZ menggunakan metode acid degumming dengan menambahkan food grade asam fosfat dengan dosis 0,045 \%. Fungsi dari penambahan asam fosfat adalah untuk mengikat kotoran khususnya senyawa phospholipid/fosfatida pada CPO yang merupakan sumber rasa dan warna yang tidak diinginkan dan dapat menyebabkan umur simpan minyak semakin pendek.Penambahan asam fosfat dilakukan pada tangki berpengaduk sentrifugal (mixer tank) pada suhu $90-110^{\circ} \mathrm{C}$ dengan tujuan untuk menghomogenkan campuran CPO dan asam phospat dengan waktu tinggal sekitar 15-30 menit dengan laju aliran asam phospat sama dengan 0,05-1\% laju aliran CPO.

Faktor suhu, kecepatan pengadukan, dan konsentrasi asam fosfat berpengaruh terhadap proses penghilangan getah (degumming) pada CPO. Berdasarkan penilitiannya, semakin tinggi suhu pada proses degumming, maka gum yang terambil dari minyak akan semakin besar sehingga konsentrasi gum semakin berkurang. Hal ini dikarenakan asam fosfat akan bereaksi dengan gum dan terpisah dari minyak. Namun, penggunaan asam fosfat yang terlalu banyak dapat merusak minyak, karena sisa asam fosfat yang tidak bereaksi mengakibatkan kenaikan nilai FFA pada minyak, sehingga penggunaan asam fosfat untuk proses degumming ini harus diperhatikan. Selain itu, jika dosis asam fosfat kekurangan atau kelebihan dapat memicu warna hitam pada minyak pada saat proses deodorisasi. Semakin tinggi kecepatan pengadukan, maka konsentrasi sisa gum yang terdapat pada minyak akan semakin berkurang. 


\section{Bleaching Process}

Setelah proses degumming, selanjutnya adalah proses bleaching/pemucatan. Proses bleaching bukan hanya terfokus pada pemucatan warna pada CPO, tetapi juga penyerapan (adsorbtion) impuritis dan kestabilan produk akhir. Jadi, dapat didefinisikan bahwa proses pemucatan sebenarnya bertujuan untuk menyerappigmen warna, suspensi koloid, gum-gumyang telah diendapkan oleh asam fosfat saat degumming, moisture, bahan-bahan oksidatif, dan trace metals melalui prinsip adsorbsi dengan menggunakanbleaching agent(adsorben) (tanah pemucat, lempung aktif atau arang aktif, dan silica gel).

Pada plant refinery PT XYZ, adsorben yang digunakan adalah jenis tanah liat (activated clay) atau disebut juga bleaching earth.Biasanya, pada penggunaan bleaching earth, tidak seluruh warna dihilangkan, tetapi kebanyakan warna dihilangkan pada proses pemucatan termal pada proses deodorisasi.Daya pemucat bleaching earth disebabkan keberadaan ion $\mathrm{Al}_{3}+$ pada permukaan partikel penyerap sehingga dapat mengadsorpsi zat warna.

Tahapan bleachingdilakukan pada tekanan vakum sebesar $<50$ mbar untuk mengurangi kuantitas zat oksidator dan kadar air; dan dengan suhu $115-120^{\circ} \mathrm{C}$ untuk menurunkan viskositas dan mempercepat kinetika adsorbsi dari minyak tersebut dalam waktu 15- 30 menit. Kemudian, bleaching earth yang telah terpakai akan disaring pada tahap filtrasi, dinamakan sebagai spent bleaching earth. Spent Bleaching Earth (SBE) tergolong sebagai limbah padat yang masih mengandung 2030\% minyak.SBE juga tergolong dalam kelompok limbah B3 (Bahan Beracun dan Berbahaya) karena memiliki sifat yang mudah terbakar.Untuk penanganan limbah SBE, PT XYZ menempatkan limbah ini pada tempat yang disediakan untuk penampungan limbah.

Proses bleaching pada proses pemurnian minyak CPO tergolong tahapan paling mahal, karena sebagian besar cost bahan chemicalpada proses pemurnian,digunakan pada pemilihan dan jumlah bleaching agent. Di samping itu, terjadi loss oil pada proses ini, yaitu sebanyak 20-30\% minyak berada pada SBE.

\section{a. Bleaching time}

Bleaching time atau disebut juga dengan periode proses bleaching adalah salah satu parameter yang dapat dikontrol pada saat proses bleaching berlangsung. Warna dan jumlah kadar FFA menurun seiring dengan penambahan dosis bleaching earth, tetapi bilangan peroksida berkurang setelah proses bleaching berlangsung 30 menit.

\section{b. Bleaching Earth Dosage}

Dosis bleaching earth merupakan salah satu faktor penting yang berpengaruh pada efisiensi dan cost pada proses bleaching. Hubungan antara dosis bleaching earth dengan pengurangan warna merah. Warna dari minyak cenderung menurun seiring dengan penambahan dosis bleacing earth. Dosis bleacing earth optimal sangat bergantung pada kuantitas dan jumlah bahan pengotor alami dari suatu minyak kelapa sawit.

\section{c. Hubungan antara proses degumming dan bleaching}

Proses degumming sangat mempengaruhi proses bleaching. Proses degumming penting dilakukan terlebih dahulu sebelum proses bleaching karena untuk meningkatkan efisiensi adsorben. Dimanaadsorben adalah zat padat yang dapat menyerap partikel fluida dalam suatu proses adsorpsi. adsorben bersifat spesifik dan terbuat dari bahan-bahan yang berpori. pemilihan jenis adsorben dalam proses adsorpsi harus disesuaikan dengan sifat dan keadaan zat yang akan diadsorpsi dan nilai komersilnya. Gum harus dilepas terlebih dahulu pada saat proses degumming karena partikel ini dapat bersaing untuk ruang pada permukaan adsorben. Ini

UNITEK. Vol. 12 No. 1 Januari - Juni 2019 | p-ISSN 2089-3957 | e-ISSN 2580-2585 
menunjukkan bahwa, proses degumming sangat mempengaruhi efektivitas dari proses bleaching. Dengan mengefisiensikan proses degumming, dapat mengurangi konsumsi bleaching earth sampai dengan 50\%.

Model tahapan proses sebelum proses filtrasi, yaitu:

Pertama, asam fosfat didosis dan dicampurkan terlebih dahulu dengan sebagian CPO sebelum masuk ke vessel mixer untuk dicampurkan lebih lanjut. Setelah itu, Campuran CPO dengan asam fosfat dialirkan ke dalam vessel bleacher, dimana dosis bleaching earth terjadi pada vessel bleacher tersebut. Proses berlanjut ke filtrasi, dimana gum dan spent earth secara bersamaan disaring oleh Niagara filter dan polishing filter.

\section{d. Filtration}

Filtrasi (penyaringan) adalah penyaringan BPO (bleached palm oil) dari hasil gum yang telah terikat dengan asam fosfat dan absorben bekas pakai (SBE). Pertama-tama, penyaringan dilakukan oleh leaf filter (Niagara filter). Niagara filter merupakan mesin filtrasi dengan menggunakan filter berbentuk daun (leaf) yang dilapisi dengan membran semipermeabel sebagai filter cloth. Pada niagara filter plantrefinery PT ASK, leaf filtertersusun secara vertikal. Minyak mengalir melalui celah leaf filteryang disusun secara seri dan turun ke bawah tangki terkumpul pada pipa kolektor minyak dalam bentuk BPO. Sementara spent earthakan melekat di permukaan leaf filter. Selama proses filtrasi pada niagara, temperatur harus dijaga antara $80-120^{\circ} \mathrm{C}$ agar proses filtrasi berjalan efektif.

Pada proses di niagara filter, terjadi 9 tahapan sebelum BPO masuk sampai sesudah BPO difiltrasi, yaitu:

\section{Standby}

Artinya Niagara Filter dalam keadaan kosong dan siap untuk digunakan, tidak ada valve yang dibuka dan pompa dalam keadaan off.

2. Vacum

Pada tahap ini NiagaraFilter dikosongkan dengan cara menghisap/menarik udara/steam keluar oleh Valve V.02 menuju tank T.611. Udara harus dikeluarkan karena dapat menyebabkan proses oksidasi pada minyak selama proses penyaringan sehingga minyak menjadi hangus. Minyak yang hangus pada proses ini akan mengurangi kualitasnya dan oengolahan lebih lanjut akan membutuhkan energi dan biaya yang lebih tingg

3. Filling filter

Proses pengisian BPO ke dalam Niagara.Setelah mencapai tekanan Vacuum, maka proses selanjutnya adalah proses pengisian minyak ke dalam NiagaraFilter. CPO dan bleaching dipompakan ke NiagaraFilter sampai penuh (highlevel).Valveyang dibuka agar sisa-sisa udara pada minyak dan tangki dapat dikeluarkan. Proses ini memerlukan waktu 10 menit.

4. Backrun

Proses penjernihan, apabila belum jernih di balikkan kembali ke bleacher atau dicampur dengan minyak baru dan lama.

5. Filtration

Proses penyaringan BPO dengan menggunakan tekanan vakum. Minyak mengalir melalui celah leaf filteryang disusun secara vertikal dan turun ke bawah tangki terkumpul pada pipa kolektor minyak. Sedangkan spent bleaching earth dan sisa gum akan menempel pada filter cloth.

6. Circulation

Proses sirkulasi BPO dengan cara mengalirkan minyak tersebut ke dalam tangki vessel bleacher. Proses ini hanya dilakukan apabila vessel dalam keadaan low.

7. Empty Filter 
Proses pengosongan BPO, dengan cara mengalirkannya ke tangki penampungan sementara, slope tank.

8. Cake Drying

Proses pengeringan SBE yang menempel pada leaf filter dengan menggunakan steam.

9. Ventilation

Proses pengeluaran tekanan yang masih terperangkap dalam Niagara filter.

10.Discharge

Proses pengosongan niagara filter dengan cara menggetarkan leaf filter menggunakan fibrator sehingga SBE dapat keluar dari Niagara filter menuju ke tempat penampungan SBE.Selanjutnya, BPO yang telah difiltrasi dari Niagara filter pada tangki penampungan, dan selanjutnya dipompa menuju filter bag dan filtercatridge.

\section{e. Deodorization Section 1 (Heating and Pre-Stripper)}

Secara umum, deodorisasi merupakan proses untuk memisahkan aroma dan bau dari minyak. Prinsip dari proses deodorisasi yaitu distilasi dengan penculutan stripping agent dalam keadaan hampa udara (vakum) dan suhu tinggi $\left(>200{ }^{\circ} \mathrm{C}\right.$ ). Stripping agent yang digunakan pada plant PT ASKadalah superheated steam. Tujuan menggunakan stripping agent adalah untuk memudahkan penguapan semua komponen-komponen volatile pada minyak dan mencegah hidrolisis pada minyak.

Stripping agent bertindak sebagai carrier gas yang akan bercampur dengan minyak sehingga menfasilitasi proses pertukaran massa pada komponen volatil menjadi fase uap. Dengan dibantu suhu tinggi dan tekanan vakum, komponenkomponen yang menimbulkan bau mudah diuapkan, kemudian melalui aliran uap komponen-komponen tersebut dipisahkan dari minyak. Komponen-komponen yang dapat menimbulkan rasa dan bau dari minyak antara lain aldehida, keton, hidrokarbon dan minyak esensial yang jumlahnya sekitar 0.1 persen dari berat minyak. Semakin besar relative volatility atau semakin kecil konsentrasi suatu komponen, maka akan semakin mudah untuk diuapkan.

\section{f. Heating Process}

Setelah difiltrasi oleh filter bag dan filtercatridge, BPO dialirkan menujuPHE danshell dan tube heat exchanger (SHE) untuk dinaikan suhunya dari $103^{\circ} \mathrm{C}-110^{\circ} \mathrm{C}$ menjadi $240-260{ }^{\circ} \mathrm{C}$. Tujuan dari pemanasan ini adalah untuk mendapatkan parameter minyak yang siap untuk dideodorisasi.Pada suhu $240-260{ }^{\circ} \mathrm{C}$ dan tekanan vakum, komponen-komponen seperti FFA, aldehida, keton, hidrokarbon lebih mudah menguap dan pigmen karotenoid lebih mudah pecah.

\section{g. Pre-Stripper}

Setelah proses pemanasan BPO sampai suhu $240-260{ }^{\circ} \mathrm{C}$, minyak dipompakan menuju ke mesin pre-stripper untuk dideodorisasi tahap pertama. Minyak masuk menuju ke dalam mesin pre-stripper dengan cara disebarkan ke dalam packing column sehingga membuat luas permukaan minyak menjadi lebih luas. Selain itu, penggunaan packing column dapat mengurangi penggunaan pelucutan steam.Mesin ini menggunakan prinsip distilasi vakum, yaitu pemisahan berdasarkan titik uap masing-masing komponen di dalam minyak dengan suhu tinggi pada tekanan vakum. Pada proses deodorisasi pada mesin pre-stripper, hanya digunakansebagian kecil steam, yaitu terdapat pada coil bagian bawah packing column. Hal ini disebabkan, fokus utama pada mesin pre-stripper adalah menguapkan komponen yang paling mudah tervolatil pada minyak, yaitu FFA, yang akan berkurang dari 3$5 \%$ sampai dengan di bawah $0,5 \%$. Oleh karena itu, tidak diperlukan jumlah steam 
dalan jumlah yang besar.Sebagian besar stripping agent digunakan pada saat deodorisasi tahap kedua pada deodorizer.

FFA dan impuritis yang tervolatil akan diserap dan ditangkap oleh sistem vakum (scrubber) yang terdapat pada bagian atas mesin pre-stripper. Uap yang ditangkap oleh scrubberakan menjadi produk samping (by product) yaitu PFAD (Palm Fatty Acid Distillate). PFAD merupakan produk hasil samping dari proses RBDPO minyak.

\section{h. Deodorization Section 2}

Deodorisasi pada tahap inimenggunakan pelucutan oleh uap air (steam). Uap panas yang digunakan merupakan uap kualitas baik (1-3\% dari minyak), yang dibangkitkan dari air umpan yang telah dideaerasi dan mengalami perlakuan tertentu, yang kemudian diinjeksikan ke dalam minyak pada suhu tinggi (252-266 $\left.{ }^{\circ} \mathrm{C}\right)$ dan kevakuman tinggi $(<6 \mathrm{mmHg})$. Pada kondisi ini, akan terjadi 3 kombinasi proses, yaitu distilasi uap, deodorisasi, dan pemucatan termal. Pada kondisi distalasi uap dan deodorisasi, peroksida terdekomposisi dan asam-asam lemak bebas (FFA) serta senyawa-senyawa odor akan teruapkan. Sedangkan pada proses pemucatan oleh panas, terjadi penurunan warna pigmen penyebab warna merah jingga (karoten) dan pigmen klorofil.

Deodorisasi pada prinsipnya merupakan proses pelucutan oleh gas pelucut (steam) dalam kondisi vakum pada suhu tertentu. Dan selama proses tersebut asamasam lemak bebas dan komponen-komponen odor dihilangkan untuk mendapatkan minyak yang tidak berbau. Meskipun proses ini secara umum dinamakan deodorisasi, tetapi sebenarnya merupakan kombinasi dari tiga operasi yang berbeda:

a) Distilasi, yaitu pelucutan komponen volatil (asam lemak bebas, tokoferol, tokotrienol, sterol, dan kontaminan seperti pestisida atau hidrokarbon aromatik polisiklik ringan, $d s b$ )

b) Deodorisasi sebenarnya, yaitu penghilangan komponen penyebab bau; dan

c) Thermal Bleaching, seperti degradasi pigmen penyebab warna oleh panas sementara menjaga efek samping reaksi seperti cis-trans isomerisasi, polimerisasi, dsb.

Beberapa literatur, menyatakan bahwa pada saat proses deodorisasi, kemungkinan besar terjadinya reaksi-reaksi yang tidak diinginkan, seperti cis-trans isomerisasi, polimersisasi dsb. Tidak bisa dimungkiri bahwa, permintaan konsumen akan produk minyak goreng yang sehat, terbebas akan asam lemak trans dan senyawa 3-MCPD ester semakin meningkat. Pada komersial plant refinery palm oil, tidak lebih dari 0,6\% dari total asam lemak trans yang dilaporkan pada saat kondisi deodorisasi dengan suhu $260-275{ }^{\circ} \mathrm{C}$ dan waktu tinggal selama 45-90 menit. Tahap deodorisasi dapat meningkatkan kadar 3-MCPD ester pada minyak sawit mentah (CPO), yaitu menjadi sekitar 4-5 mg/kg. Oleh karena itu,diperlukan kajian lebih lanjut dalam pengendalian proses deodorisasi agar tetap menjaga kualitas dan mutu yang diinginkan konsumen.

\section{Simpulan}

Proses produksi minyak CPO yang dilakukan pada plant refinery PT XYZ adalah proses pemurnian (refine) dan pemisahan (fractionation). Proses pemurnian, adalah proses mengubah CPO menjadi RBDPO, meliputi tahap degumming dengan asam fosfat, bleaching dengan activated bleaching earth, dan deodorisasi dengan menggunakan stripping agent berupa steam. Tujuan dari proses pemurnian adalah untuk meningkatkan kualitas dan mutu minyak dengan cara menghilangkan komponen-komponen minor yang dapat mempengaruhi kualitas dan stabilitas minyak. PT XYZ menggunakan metode pemurnian physical refining. Proses refinery

UNITEK. Vol. 12 No. 1 Januari - Juni 2019 | p-ISSN 2089-3957 | e-ISSN 2580-2585 
yang dilakukan meliputi pengikatan gum (degumming), pemucatan (bleaching) dengan bleaching earth, dan penghilangan beberapa komponen (deodorisasi)

\section{DAFTAR PUSTAKA}

Naibaho,P.M. 2012. Teknologi Pengolahan Kelapa Sawit. Pusat Penelitian Kelapa Sawit. Medan

Nadhifatul Latifah dan Teti Estiasih. 2016. Mikroenkapsulasi Fraksi Tidak Tersabunkan (Ftt) Distilat Asam Lemak Minyak Sawit (Dalms) Menggunakan Metode Pengeringan Semprot.Universitas Brawijaya Malang. Jurnal Pangan dan Agroindustri Vol. 4 No 1

Taylor, D. R. (2005). Bleaching. In: Bailey's Industrial Oil and Fat Products. 6th ed. (Ed. F. Shahidi). A John Wiley \& Sons, Inc. New Jersey.

Strayer, D., Maury B., Tom D., Bob D., Jeffrey F., Brent F., Pete F., Carl H., Jan Hughes., Frank K., Linsen L., Thomas M., Don M., Gerald M., Mark N., Ed P., Phil R., Tom T.., Bob W., and Jeff W. (2006). Food Fats and Oils. 9th ed. Institute of Shortening and Edible Oils. Washington DC.

Lin, L. and S. S. Koseoglu. (2005). Membrane Processing of Fats and Oils. In: Bailey's Industrial Oil and Fat Products. 6th ed. (Ed. F. Shahidi). A John Wiley \& Sons, Inc. New Jersey.

Gibon, V., Wim D. Greyt, and M. Kellens. (2007). Palm Oil Refining. European Journal of Lipid Science and Technology Vol 109: 315-335.

Basiron, Y. (2005). Palm Oil. In: Bailey's Industrial Oil and Fat Products. 6th ed. (Ed. F. Shahidi). A John Wiley \& Sons, Inc. New Jersey. 